\title{
EVALUASI SISTEM PENERIMAAN KAS DAN PENGELUARAN KAS PADA PT PLN (PERSERO) DISTRIBUSI AREA BALI UTARA
}

\author{
Deny Salam \\ Jurusan Akuntansi Program Diploma III, \\ Universitas Pendidikan Ganesha, Singaraja \\ denysalam@gmail.com
}

\begin{abstract}
Abstrak
Penelitian ini bertujuan untuk mengetahui : Evalusi sistem penerimaan dan pengeluaran kas yang terdapat pada PT PLN (Persero) Distribusi Area Bali Utara. Teknik pengumpulan data menggunakan metode observasi dan wawancara. Data yang digunakan adalah data kualitatif berupa data sistem penerimaan kas dan pengeluaran kas kecil. Selanjutnya data dianalisis dengan mengunakan analisis deskriptif kualitatif. Subyek penelitian ini adalah PT PLN (Persero) Distribusi Area Bali Utara.

Hasil penelitian menunjukan bahwa Penerimaan dan pengeluaran kas kecil pada PT PLN (Persero) Distribusi Area Bali Utara telah dilaksanankan melalui proses komputerisasi yaitu untuk penerimaan kas sendiri diterima via ATM dan untuk pengeluaran kasnya yaitu dengan sistem SPARTA (Sistem Pengendalian Anggaran Terintegrasi). Dalam implementasinya SPARTA sendiri sangat membantu sistem pengeluaran kas pada PT PLN (Persero) Distribusi Area Bali Utara. Karena dengan adanya SPARTA pengeluaran kas pada PT PLN (Persero) Distribusi Area Bali Utara dapat terkendali dan kecurangan yang ada dapat diminimalisir.
\end{abstract}

Kata Kunci : Penerimaan kas, pengeluaran kas.

Abstract
This study aims to determine: Evaluation system of cash receipts and payments on PT PLN (Persero) Distribution Area North Bali. Data collection technique used observation and interview methods. The data used is qualitative data in the form of system data of cash receipts and cash disbursements small. Furthermore, the data were analyzed by using descriptive qualitative analysis. The subject of this research is PT PLN (Persero) Distribution Area North Bali.

The results showed that a small Receipts and disbursements at PT PLN (Persero) Distribution Area North Bali has dilaksanankan through a computerized process that is to own the cash receipts received via ATMs and for cash expenditures that the system SPARTA (Budget Control Systems Integrated). In the implementation itself is very helpful SPARTA cash dispensing system at PT PLN (Persero) Distribution Area North Bali. Due to the presence SPARTA cash expenditure at PT PLN (Persero) Distribution Area North Bali can be controlled and that no fraud could be minimized.

Keywords: Cash Receipts, Cash Disbursements.

\section{Pendahuluan}

Masalah kas merupakan salah satu hal yang memerlukan penanganan khusus terutama dalam administrasinya karena pada prinsipnya kas mempunyai sifat liquid dan mudah dipindahtangankan. Dalam sebuah organisasi untuk memudahkan pengendalian atas penerimaan dan pengeluaran kas diperlukan suatu sistem yang dapat membantu kemudahan pengendalian atas penerimaan dan pengeluaran kas tersebut.

Organisasi perlu melakukan evaluasi terhadap sistem akuntansi penerimaan kas dan pengeluaran kas agar dalam menjalankan kegiata organisasi lebih efektif dan efisien. Salah satu organisasi yang melakukan evaluasi penerimaan dan pengeluaran kas adalah PT PLN (Persero) Distribusi Area Bali Utara. PT PLN (Persero) Distribusi Area Bali adalah merupakan Badan Usaha Milik Negara (BUMN) yang diberi kewenangan oleh Pemerintah dan diserahi tugas untuk melaksanakan usaha penyediaan tenaga listrik untuk kepentingan umum, dan pekerjaan usaha penunjang tenaga listrik. Dalam menjalankan usahanya, PT 
Vol. 10 NO.1 JULI 2019

p-ISSN: 2338-6177

PLN (Persero) terdiri dari beberapa proses bisnis inti yang dibagi menjadi 3 unit bisnis yaitu unit bisnis pembangkitan, unit bisnis penyaluran dan unit bisnis distribusi.

Sistem penerimaan kas dan pengeluaran kas yang digunakan oleh PT PLN (Persero)

Distribusi Area Bali Utara sudah cukup memadai yaitu sistemnya sudah menggunakan komputer yang dinamakan SPARTA. Meskipun begitu beberapa kesalahan pasti pernah terjadi, dan tindakan yang tidak sesuai prosedur tentunya juga pernah dilakukan. Untuk meminimalisir beberapa kecurangan yang dilakukan maka dari itu, evaluasi terhadap sistem penerimaan dan pengeluaran kas terhadap PT PLN (Persero) Distribusi Area Bali Utara perlu dilakukan agar nanti tidak ada penyimpangan terhadap penerimaan dan pengeluaran kas tersebut.

\section{Metode Penelitian}

Sebelum melakukan penelitian, hal pertama yang harus dilakukan yaitu menentukan lokasi penelitian dimana lokasi penelitian yang dipilih penulis yaitu pada PT. PLN (PERSERO) yang beralamat di Jalan Udayana No.27 Singaraja. Setelah menentukan lokasi penelitian, selanjutnya penulis melihat hal-hal apa saja yang terjadi pada PT. PLN terkait dengan sistem penerimaan kas dan pengeluaran kas. Setelah itu, penulis dapat merumuskan masalah dari penelitian yang akan diambil. Kemudian penulis membuat kajian teori dimana dari kajian teori inilah penulis dapat mengetahui data-data apa saja yang dibutuhkan. Data yang digunakan dalam penelitian ini berupa data kualitatif yang berasal dari hasil wawancara penulis dengan staf karyawan/karyawati PT. PLN (Persero) Distribusi Area Bali Utara. Data yang telah diperoleh kemudian dianalisis menggunakan analisis deskriptif kualitatif. Dari pengolahan data tersebut, penulis mendapatkan hasil penelitian dimana dari hasil penelitian tersebut penulis dapat menarik kesimpulan terkait dengan sistem penerimaan kas dan pengeluaran kas PT. PLN (Persero) Distribusi Area Bali Utara.

\section{Hasil dan Pembahasan}

Dalam prosedur penerimaan kas yang dilakukan oleh PT PLN (Persero) Distribusi Area Bali Utara sangat sederhana. Penerimaan kas pada PT PLN (Persero) Distribusi Area Bali Utara hanya berasal dari PT PLN Kantor Pusat yang berada di Jakarta. Dalam setiap bulannya PT PLN (Persero) Distribusi Area Bali Utara membuat permintaan anggaran yang nantinya akan dikirim ke PT PLN Distribusi Bali disetujui lalu diteruskan ke PT PLN Kantor Pusat untuk disetujui lagi dalam pencairan dana. Lalu setelah disetujui PT PLN Kantor Pusat Akan mengirimkan dananya melalui ATM yang nantinya setiap minggunya akan di ambil oleh PT PLN (Persero) Distribusi Area Bali Utara dan digunakan untuk membeli keperluan ATK dan lainnya. Jadi penerimaan kas kecil pada PT PLN (Persero) Distribusi Area Bali Utara berbeda dengan teori yang dijelaskan dikarenakan penerimaan kas kecil pada PT PLN (Persero) Distribusi Area Bali Utara hanya melalui via ATM. Sedangkan secara teori penerimaan kas kecil harus melalui prosedur yaitu dari bagian utang, bagian kasir, bagian pemegang dana kas kecil lalu ke bagian akuntansi. Pengeluaran kas pada PT PLN (Persero) Distribusi Area Bali Utara sendiri telah menggunakan sistem SPARTA dengan sistem SPARTA ini kecurangan dalam pengeluaran kas sendiri akan terhindar.

Prosedur pengeluaran kas kecil pada PT PLN (Persero) Distribusi Area Bali Utara langsung melalui sistem. Jadi jika dibandingkan dengan teori sebenarnya pengeluaran kas kecil sendiri yaitu mengisi formulir surat permintaan pengeluaran dana kas kecil sebanyak 2 lembar untuk selanjutnya diserahkan kepada pemegang dana kas kecil. Lalu menerima uang tunai dan surat permintaan pengeluaran dari pemegang dana kas kecil. Setelah itu mengumpulkan bukti-bukti penggunaan dana kas kecil untuk dijadikan pendukung bukti pengeluaran kas kecil. Selanjutnya mengisi formulir bukti pengeluaran kas kecil berdasarkan data bukti pendukung. menyerahkan bukti pengeluaran kas kecil, bukti pendukung dan surat permintaan pengeluaran dana kas kecil lembar 1 kepada pemegang dana kas kecil. Terakhir menerima surat permintaan pengeluaran dana kas kecil lembar ke 2 yang telah di cap lunas dari pemegang dana kas kecil untuk di arsipkan. 
Vol. 10 NO.1 JULI 2019

p-ISSN: 2338-6177

\section{Simpulan dan Saran}

Adapun kesimpulan yang didapatkan dari penelitian ini yaitu, sistem penerimaan kas kecil pada PT PLN (Persero) Distribusi Area Bali Utara bersumber dari PT PLN Pusat. Kas yang diterima akan ditransfer atau di dropping melalui Bank (Bank Bukopin) setiap bulannya sesuai permintaan anggaran yang telah disetujui. Yang pengambilannya melalui via ATM.

Sistem pengeluaran kas kecil pada PT PLN (Persero) Distribusi Area Bali Utara semuanya dilakukan dengan komputerisasi melalui sistem yang disebut dengan sistem SPARTA (Sistem Pengendalian Anggaran Terintegrasi) dan tidak ada pengeluaran yang tidak melalui proses verifikasi dan otorisasi dari pejabat yang berwenang. Keandalan pengeluaran didukung dengan pengendalian intern yang sangat baik dan praktek yang sehat dalam melaksanakan tugas masing-masing fungsi serta didukung dengan adanya karyawan yang mutunya sesuai dengan tanggung jawabnya sehingga terjadinya korupsi dapat dihindari.

Sedangkan saran yang dapat diajukan adalah sebaiknya didalam sistem penerimaan dan pengeluaran kas pada PT PLN (Persero) Distribusi Area Bali Utara agar lebih berhatihati terutama sebelum melakukan pengeluaran kas. Walaupun melalui SPARTA pengecekan manual yang lebih teliti masih diperlukan agar lebih mudah dalam mempertanggungjawabkan pengeluaran. Terkait dengan penerimaan kas agar dilakukan juga control ataupun pengecekan oleh bagian yang terkait agar yang diterima juga nantinya dapat dipertanggung jawabkan.

\section{DAFTAR PUSTAKA}

Admin. 2012. Unsur Sistem Akuntansi. Tersedia pada http://ilmuakuntansi.web.id/unsursistem-akuntansi/

Ainiqurotul. 2013. Pengertian penerimaan kas. Tersedia pada https://aniqurotul.wordpress.com/2013/03/25/pengertian-penerimaan-kas/

Admin. 2012. Pengertian Sistem Akuntansi. Tersedia pada http://ilmuakuntansi.web.id/pengertian-sistem-akuntansi/

Blogger. 2009. "Sistem Akuntans". Tersedia pada http://sistemakuntansi1000.blogspot.co.id/2009/08/pengertian-sistem.html

Ermayanti, D. 2009. Sistem penerimaan dan pengeluaran kas. Tersedia pada https://dwiermayanti.wordpress.com/2009/10/16/sistem-penerimaan-dan-pengeluarankas/

Raharjo, K. B. 2013. Pemahaman SPI (Sistem Pengendalian Intern). Tersedia pada https://kurniawanbudi04.wordpress.com/2013/01/14/pemahaman-spi-sistempengendalian-intern/

Sipahutar. 2012. System Informasi Akuntansi Pengeluaran Kas. Tersedia pada https://sipahutar91.wordpress.com/2012/07/02/bab-ii-sistem-informasi-akuntansipengeluaran-kas/

Vinda, A. 2011. Prosedur pengeluaran dana kas kecil. Tersedia pada http://vindamystory.blogspot.co.id/2011/12/prosedur-pengeluaran-dana-kas-kecil.html 